\title{
Editorial: The Earliest-Born Cortical Neurons as Multi-Tasking Pioneers: Expanding Roles for Subplate Neurons in Cerebral Cortex Organization and Function
}

\author{
Makoto Sato ${ }^{1,2 \star}$ and Shen-Ju Chou ${ }^{3}$ \\ ${ }^{1}$ Department of Anatomy and Neuroscience, Graduate School of Medicine, Osaka University, Suita, Japan, ${ }^{2}$ Division of \\ Developmental Neuroscience, United Graduate School of Child Development, Osaka University, Suita, Japan, ${ }^{3}$ Institute of \\ Cellular and Organismic Biology, Academia Sinica, Taipei, Taiwan
}

Keywords: cerebral cortex, development, layer 6b, neocortex, subplate

\author{
Editorial on the Research Topic
}

The Earliest-Born Cortical Neurons as Multi-Tasking Pioneers: Expanding Roles for Subplate Neurons in Cerebral Cortex Organization and Function

The subplate is a unique layer in the mammalian neocortex. It consists of the earliest-born neurons in the neocortex and undergoes a massive reduction in the number of neurons during postnatal development. The subplate is also characterized by its heterogeneity in cell morphology,

OPEN ACCESS

Edited by:

Zoltan Molnar,

University of Oxford, United Kingdom

Reviewed by:

Zdravko Petanjek,

University of Zagreb, Croatia

Robert Francis Hevner,

University of California, San Diego,

United States

*Correspondence:

Makoto Sato

makosato@anat2.med.osaka-u.ac.jp

Received: 22 May 2020

Accepted: 25 June 2020

Published: 25 August 2020

Citation:

Sato M and Chou S-J (2020) Editorial: The Earliest-Born Cortical Neurons as Multi-Tasking Pioneers: Expanding

Roles for Subplate Neurons in Cerebral Cortex Organization and

Function. Front. Neuroanat. 14:43. doi: 10.3389/fnana.2020.00043 incomparable gene expression pattern, and an early functional maturation. This diversity in form and function is evident in its role in circuit formation processes between the cortex and thalamus and also within a local cortical area above it. Disruptions of the subplate can lead to neurodevelopmental deficits such as autism spectrum disorder.

Postmitotic neurons born in the ventricular zone first form the preplate together with Cajal-Retzius cells, which originate from three distinct regions of the dorsal telencephalon (reviewed in Barber and Pierani, 2016). The preplate is then split, by later-born neurons coming in between to form the cortical plate, into the marginal zone at the surface (containing Cajal-Retzius cells) and the subplate at the base of the cortical plate. Although most of the subplate neurons are early born preplate neurons in rodents, the vast majority of subplate neurons are generated during mid-gestation in primates (Duque et al., 2016). While many subplate neurons are lost during postnatal development, not all of them disappear. Recent morphological and gene expression studies have provided evidence that layer $6 \mathrm{~b}$ in the adult (or juvenile) cortex contains remnant subplate neurons (Hoerder-Suabedissen et al., 2013; Marx et al., 2017). Subplate neurons exhibit morphological heterogeneity in the somatodendritic structure. In addition to typical pyramidal neurons found in layers 2-6a; horizontal cells, multipolar cells, inverted pyramidal cells, fusiform cells, and polymorphous cells are among those reported in the subplate (Mrzljak et al., 1988; Hanganu et al., 2002). These cell types are maintained between the early postnatal subplate and juvenile layer $6 \mathrm{~b}$ despite a decrease in their abundance (Marx et al., 2017). The subplate is more than a transient embryonic structure. In primates, the subplate is much thicker, and subplate neurons remain as "interstitial cells" in the white matter (Kostovic and Rakic, 1990), suggesting prominent roles of subplate neurons in primates. As pyramidal neurons increase in abundance in layer $6 \mathrm{~b}$, it is suggested that layer $6 \mathrm{~b}$ consists of remnant subplate neurons and cortical pyramidal neurons. Interestingly, intermediate 
progenitor cells expressing Tbr2 contribute to projection neurons in all layers, including preplate Cajal-Retzius neurons and the subplate (Vasistha et al., 2015; Mihalas et al., 2016), suggesting that pyramidal neurons that increase in juveniles might derive from Tbr2-expressing progenitors.

Transcriptomic analyses of cortical neurons and those focused on subplate neurons, identified genes specifically expressed in subplate/layer $6 \mathrm{~b}$ with a differential time course (Bernard et al., 2012; Oeschger et al., 2012; Hoerder-Suabedissen et al., 2013; Tasic et al., 2016). A cell clustering analysis based on single cell RNAseq data classified layer $6 \mathrm{~b}$ cells into two cell types (Tasic et al., 2016). Molecular markers for subplate/layer $6 \mathrm{~b}$ neurons, however, have been shown to be expressed in overlapping populations (Hoerder-Suabedissen and Molnár, 2013; Tiong et al.), making it difficult to correlate gene expression profiles with cellular morphology, neuronal connection patterns, and electrophysiological properties.

During the embryonic stage, the subplate serves as a critical interface between cortical neurons and incoming thalamocortical axons. Thalamocortical axons transiently connect with subplate neurons before they enter the cortical plate and finally reach layer 4 (Kostovic and Goldman-Rakic, 1983; Kageyama and Robertson, 1993; Herrmann et al., 1994). This transient connection is functional, as thalamic stimulations in the thalamocortical slices from rat embryos induce responses in subplate neurons (Higashi et al., 2002; Molnár et al., 2003), indicating the early maturation of subplate neurons. Furthermore, subplate neurons contain positional cues for thalamic axons to target appropriate cortical areas. When the areal identity is disorganized by mis-expressing cortical patterning molecule FGF8, in the subplate as well as in cortical plate, thalamic axons run longer in the subplate before they turn into the cortical plate (Shimogori and Grove, 2005). On the other hand, projection to the thalamus by subplate neurons was thought to pioneer the corticothalamic projections by neurons in layers 5 and 6 . At least in ferrets, however, axons of layer 5 neurons arrive at the thalamic nuclei earlier than those of subplate and layer 6 neurons (Clascá et al., 1995), arguing against the pioneering function of subplate axons. Additionally, the subplate (layer 6b) also shapes corticofugal pathways (Grant et al., 2012) and callosal connections (deAzevedo et al., 1997). For example, retinal inputs regulate layer $6 \mathrm{~b}$ neuronal projections, which may in turn influence the projection of layer 5 neurons (Grant et al., 2016).

Subplate neurons are also indispensable for local network formation, especially in the primary sensory areas. For example, ablation of the subplate in the visual cortex affects ocular dominance column formation by affecting the maturation of thalamocortical connections to layer 4 (Ghosh and Shatz, 1992; Kanold and Shatz, 2006).

In addition to the foundational studies described above, recent work has revealed new aspects of the subplate function and form, such as modulation of radial migration of later-born neurons
(Ohtaka-Maruyama et al., 2018), extra-cortical origins (Pedraza et al., 2014), and fate selection of later-born neurons (Ozair et al., 2018). This Research Topic entitled The Earliest-Born Cortical Neurons as Multi-Tasking Pioneers: Expanding Roles for Subplate Neurons in Cerebral Cortex Organization and Function, consists of a collection of three Review articles that provide up-to-date overviews on multiple functions of the subplate in cortical development and two Original Research articles that report novel findings in the development and function of the subplate.

Luhmann et al. summarize the electrophysiology of subplate neurons including intrinsic membrane properties and firing patterns, and input/output connection patterns of subplate neurons, discussing possible roles in cortical spindle burst and gamma oscillation.

A review by Kanold et al. explains sensory-evoked plasticity of neuronal circuits of subplate neurons during development and in pathological conditions, focusing on the silent synapses formed onto them.

In addition to the two Review articles above, a Mini Review by Ohtaka-Maruyama features a novel function of the subplate in the regulation of the migration of cortical plate neurons. This finding revealed another mechanism for mode switching of neuronal migration from slow multipolar migration to rapid locomotion, guided by radial fibers.

$\mathrm{Yu}$ et al. use conditional mouse knockouts to define new functions of a well-established subplate marker gene, Ctgf, in regulating the number and dendritic complexity of subplate neurons, and maturation of oligodendrocytes in the white matter beneath the primary somatosensory cortex.

Finally, an article by Tiong et al. identified a novel marker gene for the mouse embryonic subplate and shows that it is expressed in $80 \%$ of layer $6 \mathrm{~b}$ neurons in the primary somatosensory cortex that project axons to the primary motor cortex. This marker should be a useful tool to study functions of subplate neurons at early stages of cortical development.

The aim of this Research Topic is to highlight the versatility of the subplate in cortical development and to attract readers to this unique layer in the mammalian neocortex. We would like to thank all the contributors and readers and hope future work will elucidate developmental mechanisms and circuit functions of the subplate, which is important both scientifically and clinically.

\section{AUTHOR CONTRIBUTIONS}

All authors listed have made a substantial, direct and intellectual contribution to the work, and approved it for publication.

\section{ACKNOWLEDGMENTS}

We host editors, express our sincere thanks to Dr. Yuichiro Oka, for his essential contribution to this Editorial. He deserves to be recognized as one of the co-authors for this Editorial. 


\section{REFERENCES}

Barber, M., and Pierani, A. (2016). Tangential migration of glutamatergic neurons and cortical patterning during development: lessons from Cajal-Retzius cells. Dev. Neurobiol. 76, 847-881. doi: 10.1002/dneu.22363

Bernard, A., Lubbers, L. S., Tanis, K. Q., Luo, R., Podtelezhnikov, A. A., Finney, E. M., et al. (2012). Transcriptional architecture of the primate neocortex. Neuron 73, 1083-1099. doi: 10.1016/j.neuron.2012.03.002

Clascá, F., Angelucci, A., and Sur, M. (1995). Layer-specific programs of development in neocortical projection neurons. Proc. Natl. Acad. Sci. U.S.A. 92, 11145-11149. doi: 10.1073/pnas.92.24.11145

deAzevedo, L. C., Hedin-Pereira, C., and Lent, R. (1997). Callosal neurons in the cingulate cortical plate and subplate of human fetuses. J. Comp. Neurol. 386, 60-70. doi: 10.1002/(SICI)1096-9861(19970915)386:1<60::AID-CNE7>3. $0 . \mathrm{CO} ; 2-\mathrm{B}$

Duque, A., Krsnik, Z., Kostovic, I., and Rakic, P. (2016). Secondary expansion of the transient subplate zone in the developing cerebrum of human and nonhuman primates. Proc. Natl. Acad. Sci. U.S.A. 113, 9892-9897. doi: $10.1073 /$ pnas. 1610078113

Ghosh, A., and Shatz, C. J. (1992). Involvement of subplate neurons in the formation of ocular dominance columns. Science 255, 1441-1443. doi: 10.1126/science.1542795

Grant, E., Hoerder-Suabedissen, A., and Molnar, Z. (2012). Development of the corticothalamic projections. Front. Neurosci. 6:53. doi: $10.3389 /$ fnins. 2012.00053

Grant, E., Hoerder-Suabedissen, A., and Molnar, Z. (2016). The regulation of corticofugal fiber targeting by retinal inputs. Cereb. Cortex 26, 1336-1348. doi: 10.1093/cercor/bhv315

Hanganu, I. L., Kilb,W., and Luhmann, H. J. (2002). Functional synaptic projections onto subplate neurons in neonatal rat somatosensory cortex. $J$. Neurosci. 22, 7165-7176. doi: 10.1523/JNEUROSCI.22-16-07165.2002

Herrmann, K., Antonini, A., and Shatz, C. J. (1994). Ultrastructural evidence for synaptic interactions between thalamocortical axons and subplate neurons. Eur. J. Neurosci. 6, 1729-1742. doi: 10.1111/j.1460-9568.1994.tb00565.x

Higashi, S., Molnár, Z., Kurotani, T., and Toyama, K. (2002). Prenatal development of neural excitation in rat thalamocortical projections studied by optical recording. Neuroscience 115, 1231-1246. doi: 10.1016/S0306-4522(02)00418-9

Hoerder-Suabedissen, A., and Molnár, Z. (2013). Molecular diversity of earlyborn subplate neurons. Cereb. Cortex 23, 1473-1483. doi: 10.1093/cercor/ bhs137

Hoerder-Suabedissen, A., Oeschger, F. M., Krishnan, M. L., Belgard, T., Wang, W. Z., Lee, S., et al. (2013). Gene expression profiling of mouse subplate. Proc. Natl. Acad. Sci. U.S.A. 110, 3555-3560. doi: 10.1073/pnas.1218510110

Kageyama, G. H., and Robertson, R. T. (1993). Development of geniculocortical projections to visual cortex in rat; Evidence for early ingrowth and synaptogenesis. J. Comp. Neurol. 335, 123-148. doi: 10.1002/cne.903350109

Kanold, P. O., and Shatz, C. J. (2006). Subplate neurons regulate maturation of cortical inhibition and outcome of ocular dominance plasticity. Neuron 51, 627-638. doi: 10.1016/j.neuron.2006.07.008

Kostovic, I., and Goldman-Rakic, P. S. (1983). Transient cholinesterase staining in the mediodorsal nucleus of the thalamus and its connections in the developing human and monkey brain. J. Comp. Neurol. 219, 431-447. doi: 10.1002/cne.902190405
Kostovic, I., and Rakic, P. (1990). Developmental history of the transient subplate zone in the visual and somatosensory cortex of the macaque monkey and human brain. J. Comp. Neurol. 297, 441-470. doi: 10.1002/cne.902970309

Marx, M., Qi, M., Hanganu-Opatz, I. L., Kilb, W., Luhmann, H. J., and Feldmeyer, D. (2017). Neocortical layer $6 \mathrm{~B}$ as a remnant of the subplate - a morphological comparison. Cereb. Cortex 27, 1011-1026. doi: 10.1093/cercor/bhv279

Mihalas, A. B., Elsen, G. E., Bedogni, F., Daza, R. A. M., Ramos-Laguna, K. A., Arnold, S. J., et al. (2016). Intermediate progenitor cohorts differentially generate cortical layers and require Tbr2 for timely acquisition of neuronal subtype identity. Cell Rep. 16, 92-105. doi: 10.1016/j.celrep.2016.05.072

Molnár, Z., Kurotani, T., Higashi, S., Yamamoto, N., and Toyama, K. (2003). Development of functional thalamocortical synapses studied with current source-density analysis in whole forebrain slices in the rat. Brain Res. Bull. 60, 355-371. doi: 10.1016/S0361-9230(03)00061-3

Mrzljak, L., Uylings, H. B. M., Kostovic, I., and van Eden, C. G. (1988). Prenatal development of neurons in the human prefrontal cortex. II. A quanlitative Golgi study. J. Comp. Neurol. 271, 355-386, 485-496. doi: $10.1002 / \mathrm{cne} .902710306$

Oeschger, F. M., Wang, W.-Z., Lee, S., García-Moreno, G., Goffinet, A. M., Arbonés, M. L., et al. (2012). Gene expression analysis of the embryonic subplate. Cereb. Cortex 22, 1343-1359. doi: 10.1093/cercor/bhr197

Ohtaka-Maruyama, C., Okamoto, M., Endo, K., Oshima, M., Kaneko, N., Yura, K., et al. (2018). Synaptic transmission from subplate neurons controls radial migration of neocortical neurons. Science 360, 313-317. doi: 10.1126/science.aar2866

Ozair, M. Z., Kirst, C., van den Berg, B. L., Ruzo, A., Rito, T., and Brivanlou, A. H. (2018). hPSC modeling reveals that fate selection of cortical deep projection neurons occurs in the subplate. Cell Stem Cell 23, 60-73.e6. doi: 10.1016/j.stem.2018.05.024

Pedraza, M., Hoerder-Suabedissen, A., Albert-Maestro, M. A., Molnár, Z., and De Carlos, J. A. (2014). Ontogenic heterogeneity of the subplate. Proc. Natl. Acad. Sci. U.S.A. 111, 8613-8618. doi: 10.1073/pnas.1323816111

Shimogori, T., and Grove, E. A. (2005). Fibroblast growth factor 8 regulates neocortical guidance of area-specific thalamic innervation. J. Neurosci. 25, 6550-6560. doi: 10.1523/JNEUROSCI.0453-05.2005

Tasic, B., Menon, V., Nguyen, T., Kim, T. K., Jarsky, T., Yao, Z., et al. (2016). Adult mouse cortical cell taxonomy revealed by single cell transcriptomics. Nat. Neurosci. 19, 335-346. doi: 10.1038/nn.4216

Vasistha, N. A., García-Moreno, F., Arora, S., Cheung, A. F. P., Arnold, S. J., Robertson, E. J., et al. (2015). Cortical and clonal contribution of Tbr2 expressing progenitors in the developing mouse brain. Cereb. Cortex 25, 3290-3302. doi: 10.1093/cercor/bhu125

Conflict of Interest: The authors declare that the research was conducted in the absence of any commercial or financial relationships that could be construed as a potential conflict of interest.

Copyright $\odot 2020$ Sato and Chou. This is an open-access article distributed under the terms of the Creative Commons Attribution License (CC BY). The use, distribution or reproduction in other forums is permitted, provided the original author $(s)$ and the copyright owner(s) are credited and that the original publication in this journal is cited, in accordance with accepted academic practice. No use, distribution or reproduction is permitted which does not comply with these terms. 